\title{
Shear behavior of steel fiber reinforced concrete using full-field displacements from digital image correlation
}

\author{
Sahith Gali ${ }^{1}$, and Kolluru.V.L.Subramaniam ${ }^{2, *}$ \\ ${ }^{1}$ Indian Institute of Technology Hyderabad, Hyderabad, TS 502285, India. \\ ${ }^{2}$ Indian Institute of Technology Hyderabad, Hyderabad, TS 502285, India.
}

\begin{abstract}
Reinforced concrete beams with discrete hooked-end steel fibers at $0.5 \%$ volume fraction are tested with a shear span to depth $(\mathrm{a} / \mathrm{d})$ ratio equal to 1.8. Digital image correlation (DIC) technique was used to obtain the full-filed displacements from the beam. The formation and propagation of a shear crack which directly influences the load response and the peak load in the load response of the beam is monitored using the displacement information available from DIC. There is a continuous increase in slip across the crack faces with increasing load, which produces an increase in the crack opening. The dilatant behavior indicated by the proportion of crack opening to slip displacement obtained from the control and the SFRC beams is identical. Failure in control beams is brittle and was produced by the opening of dominant shear crack within the shear span. At the peak load, the shear crack pattern in fiber reinforced concrete is identical to the crack pattern in the control beam. The fiber reinforced concrete beams exhibit post peak load carrying capacity with continued slip of the dominant shear crack. The crack bridging stress provided by the fibers results in a significant increase shear transfer across the crack which provides significant post-peak load carrying capacity with increasing slip of the shear crack.
\end{abstract}

\section{Introduction}

Often in shear critical members, the requirement of shear reinforcement leads to close spacing of stirrups. This problem is compounded while considering the ductile detailing requirements to meet the concerns of seismic design, which requires provision of extra stirrup. The extra stirrups, often lead to heavy congestion of steel. Methods of reducing steel congestion, which provide the required capacity and ductility have often involved the use of fiber reinforcement in concrete. A survey of literature indicates that there is an increase in the load carrying capacity and ductility with the addition of steel fibers [1-12]. ACI 318 (2008) [13] allows the usage of steel fibers as minimum shear reinforcement. Most of the data in the literature has been obtained for slender beams with shear span to depth $(\mathrm{a} / \mathrm{d})$ ratios greater than 2.5 in which beam action governs the failure. There is very limited data available from beams with low a/d ratio i.e short beams for which arch action governs the failure. The

\footnotetext{
* Corresponding author: kvls@,iith.ac.in
} 
role of fibers in beams with low a/d ratio is still not clear. An a/d ratio less than 2.0 was selected to contribute additional data to the limited available data set. Further, for small a/d ratio, failure is shown to be produced by a shear crack within a small region $[2,3,9]$, which allows for studying the behavior of the shear crack.

Many researchers have proposed empirical equations for the shear strength of fiber reinforced concrete by modifying the existent equations available for the reinforced concrete beams. In all the codes the shear strength equation for reinforced concrete is given as two separate components those are the contribution coming for concrete and stirrup contribution [14-16]. Researchers have modified the concrete contribution term to propose the shear strength expression for fiber reinforced concrete. These proposed equations takes into account major factors responsible for shear behavior which includes shear span to depth ratio, percentage of longitudinal reinforcement, and other factors include volume of fibers, fibers aspect ratio, fiber geometry, fiber tensile behavior and also concrete matrix properties [1-12] [17]. All the proposed equations are empirical relations estimated from the experiments on steel fiber reinforced concrete beams and few on other types of fibers. The major effect of fiber parameters is in improving stress transfer across the crack due to the bridging action which in turn effects the post cracking behavior of concrete beam.

Addition of fibers increases the post cracking stress transfer ability in concrete, which primarily contributes to improving the ductility [18-19]. To assess the true potential of fibers the post cracking stress transfer across crack has to be accounted for. This is accounted for by including an additional term contributed by steel fibers to the total shear resistance. The post cracking stress transfer is particularly important for shear where shear transfer by aggregate interlock provides significantly to shear capacity of RC elements [20]. The slip displacement along rough cracks also results in dilatancy under shear and torsion [21-24]. The crack bridging provided by fibers can potentially provide for increased mobilization of aggregate interlock, thereby providing shear load capacity. An understanding of the influence of fibers on the post-cracking shear stress transfer across rough cracks surface and its influence on the shear capacity of reinforced concrete beams needs to be understood to develop design provisions which consider the influence of fibers on shear capacity.

Motivation for the study comes from the need to understand the role of discrete steel fiber reinforcement in contributing to the shear behavior of reinforced concrete beams. The overall objective of this study is to investigate the influence of steel fibers on the shear response of reinforced concrete. In particular, it is proposed to investigate the influence of fibers on shear behavior of beams with potential arch action. Beams with shear span to depth ratio of 1.8 was considered in the present study. The influence of the steel fibers on the shear transfer across rough cracks in concrete and its influence on the shear behavior of reinforced concrete is investigated. An approach which combines experimental and digital image analysis is presented to develop an understanding of shear response of reinforced concrete with steel fibers.

\section{Experimental program}

Reinforced concrete beams of dimensions $125 \mathrm{~mm}$ width, $250 \mathrm{~mm}$ depth and $1500 \mathrm{~mm}$ length were used in the test program. In the test program, both control and fiber reinforced concrete beams were cast for testing. These beams include three beams each of control and fiber reinforced concrete with fiber volume fractions $\left(\mathrm{v}_{\mathrm{f}}=0.5 \%\right)$. Dramix ${ }^{\mathrm{RM}} 3 \mathrm{D}$ hooked end and glued non-balling steel fibers of aspect ratio 80 (length $60 \mathrm{~mm}$ and diameter of $0.75 \mathrm{~mm}$ ) manufactured by Bekaert industries were used in this study. The fibers have a modulus of elasticity of $210 \mathrm{GPa}$ and tensile strength equal to $1225 \mathrm{MPa}$.

All beams were reinforced with two reinforcing bars of $16 \mathrm{~mm}$ diameter placed with a clear cover of $20 \mathrm{~mm}$ as shown in Figure 1. The reinforcing bars confirmed to the 
requirements of IS 1786 (2008) [25] and had a prescribed yield stress defined at $0.2 \%$ offset strain equal to $500 \mathrm{MPa}$, Elastic modulus equal to $200 \mathrm{GPa}$ and an ultimate strain equal to 0.16 . One half of the beam was reinforced with $8 \mathrm{~mm}$ closed shear stirrups at a spacing of $150 \mathrm{~mm}$. The stirrups were provided in one half of the beam to reinforce it against shear failure and to ensure that shear failure occurred only on one side of the beam. The part of the beam without shear reinforcement allowed for a closer examination of the shear crack patterns and to evaluate the mechanisms contributing to shear resistance. Closely placed stirrups with a spacing equal to $100 \mathrm{~mm}$ were also provided at the supports of beam to avoid possible anchorage failure.

All the beams were tested with a shear span to depth ratio equal to 1.8. The testing was performed using a servo-controlled test machine where the net deflection of the center of the beam was measured using LVDT. The test was performed in displacement control where the deflection of the beam was increased in a controlled manner. The loading arrangement used in this study confirmed to the requirements of ASTM 1609, which ensured that no torsion is generated in the beam due to eccentricity. The loads were applied using hardened steel rollers, which ensured perfect line loading at precisely marked locations of the beam. Each roller was attached to the actuator through individual swivel head which allowed for reducing the influence of torsion in the loading arrangement.
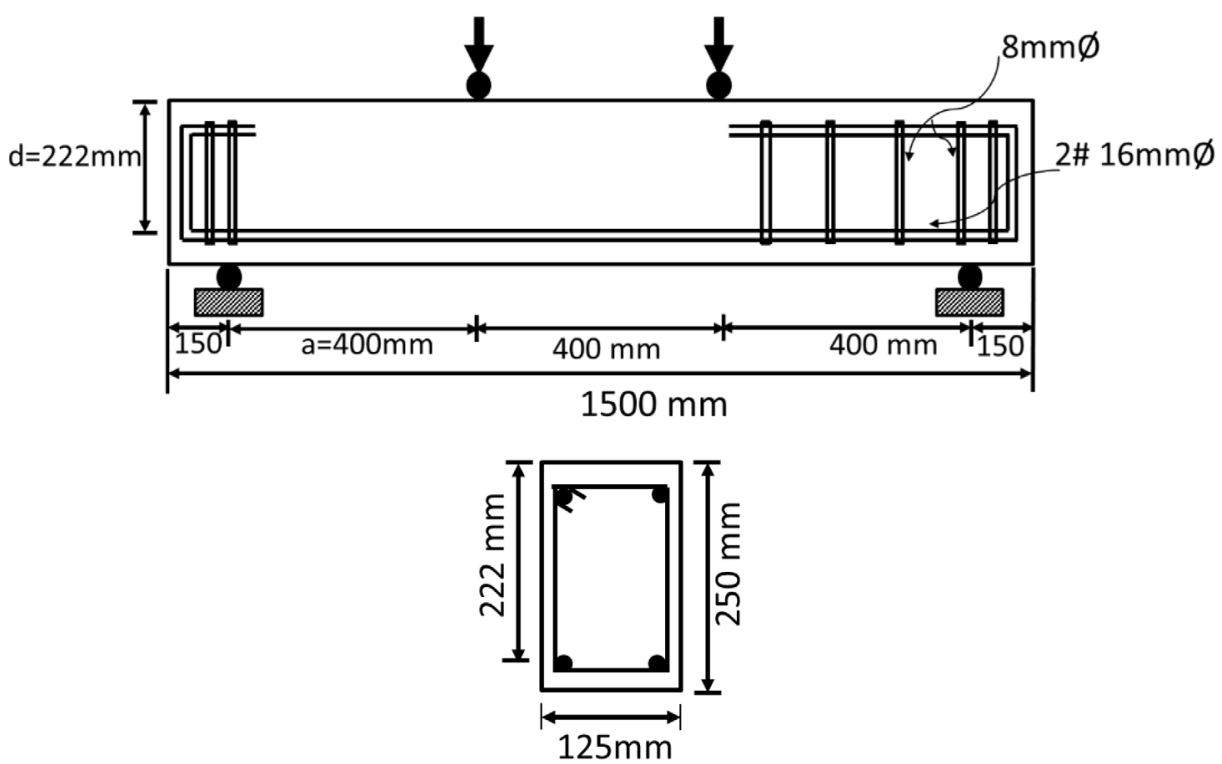

Fig. 1. The specimen geometry and the loading arragement used for shear tests.

The surface displacements, strains and development of cracks during the entire load response were determined using a digital image analysis procedure called digital image correlation. Digital image correlation (DIC) is a full-field optical technique which provides spatially continuous measurement of displacements across the surface of the specimen. DIC relies on correlation of the random pattern of speckles between images of the deformed and reference (undeformed) configurations of the specimen within small neighborhoods called subsets [27-28]. A sprayed-on speckle pattern was created on the surface of the beam without the shear stirrups. A uniform coat of white paint and after the white paint dried, the sprayedon speckle was created by spraying a black mist. 
During a test, digital images of the specimen were captured for use in digital image correlation using a high resolution camera ( 5 mega pixel), which was controlled by a computer. Uniform light intensity was ensured across the surface of the beam using normal white light. The camera was fitted with a $50 \mathrm{~mm}$ lens and was placed at a distance of $1 \mathrm{~m}$ from the specimen surface. Calibration for the pixel size was performed using a graduated rule placed in front of the specimen. From this measurement, the physical calibration was established. Typical calibration was in the range of 7-10 pixels per $\mathrm{mm}$. A reference image was captured in the undeformed state prior to the initiation of loading program. Images of the specimen were captured at regular intervals during the test. A photograph of the test setup is shown in Fig. 2(a) and a schematic figure of the DIC test setup is shown in Fig. 2(b). For the setup used in this study, the random error in the measured displacement is in the range of 0.02 pixels and a conservative estimate of the resolution in strain obtained from the digital correlation was $17 \mu \varepsilon$. [29-30]

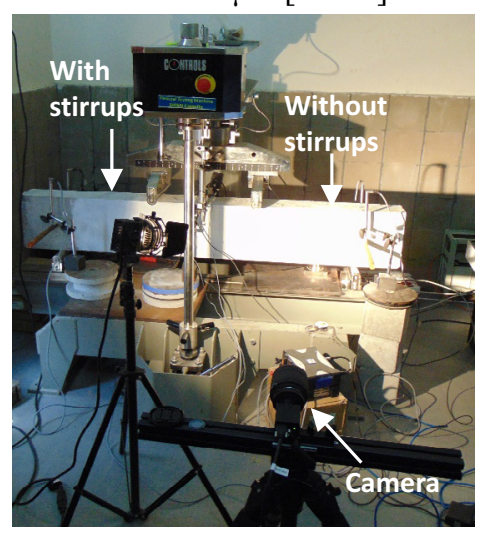

(a)

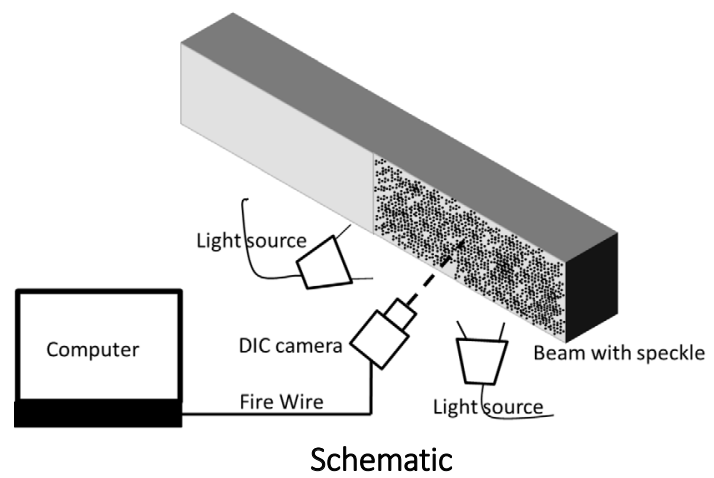

(b)

Fig. 2. (a) Photograph of the Test setup; (b) schematic of the test setup.

\section{Experimental results}

The load-deflection responses of the control and hooked end steel fiber reinforced concrete (SFRC) beams are shown in Fig. 3. Failure in control specimens was sudden, immediately after attaining the peak load and could not be controlled even in displacement control. The load response of the SFRC beams is nominally similar to the load response obtained from the control specimens up to the peak load of the control beams. In the $0.5 \%$ SFRC beams (containing $0.5 \%$ volume fraction steel fibers), there is a small increase in the peak load when compared to the control beams. After the peak load there is a continuous decrease in the load carrying capacity with increasing deflection following which, the load carrying capacity essentially levels to a constant value with increasing deflection. 


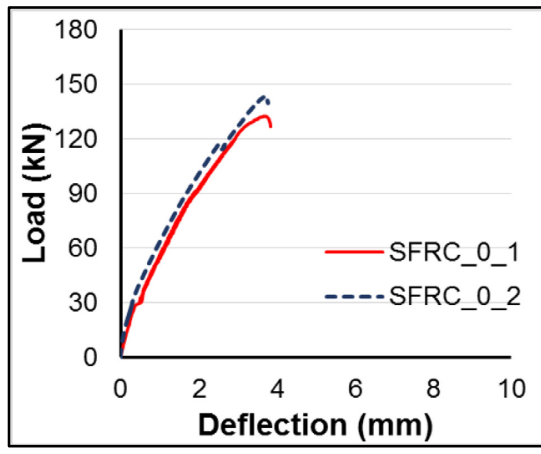

(a)

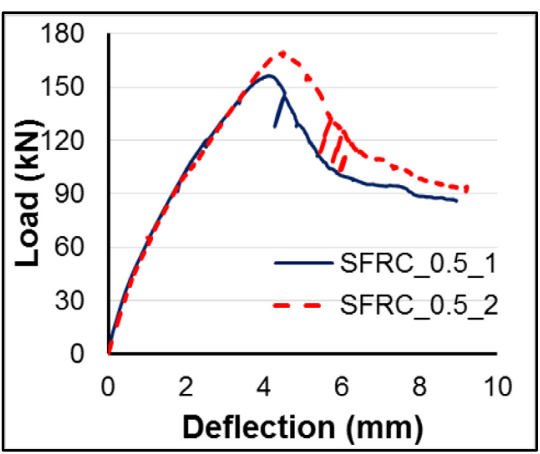

(b)

Fig. 3. Load-Deflection Response of beams: (a) Control beams; and (b) SFRC beams.

The crack patterns on the side of the beam without shear stirrups for both control and FRC beams are shown in Fig. 4. The crack patterns shown in the figure were identified visually and marked on the surface of the beam. These crack patterns were marked on the back surface, which did not have the speckle pattern. The numbers in the figure indicate the applied load. With the application of load, initially, flexural cracks were formed in the constant moment region. With an increase in load, flexural cracks increased in length and newer flexural cracks were formed along the span. In control beam (labelled SFRC_0_1), at an applied load in the range of $95-100 \mathrm{kN}$ a shear crack emanating from the flexural crack located approximately $215 \mathrm{~mm}$ from the support up to the mid-height of the beam. The crack angle was in the range 41 to 43 degrees with respect to the horizontal. The crack was located at a distance approximately equal to the depth of the beam, in the range of $230-250 \mathrm{~mm}$ from the support. With increasing load, this shear crack continued to propagate up to the top of the beam. Ultimate failure was by a crack which propagated along the rebar towards support producing splitting along the rebar. While a flexure-shear crack was also formed, it was arrested in the compression region. In $0.5 \%$ SFRC beams (labelled SFRC_0.5_1), a shear crack was also initiated from a flexural crack located approximately $210 \mathrm{~mm}$ from the support at a comparable load in the range of $100-110 \mathrm{kN}$. The location of the shear crack and the angle of the crack were also nominally similar to those observed in the control beams. At loads corresponding to the peak load in the control beams, the shear crack was fully established between the level of the flexural reinforcement and the compression region close to the top of the beam. The sudden failure by splitting along the flexural reinforcement was not observed. There was a noticeable decrease in the flexural crack spacing in SFRC beams compared to the control beams. A secondary crack was observed to form from the support close to the peak load and it joined with the main shear crack. The shear crack continued to open with increasing deflection after the peak load.

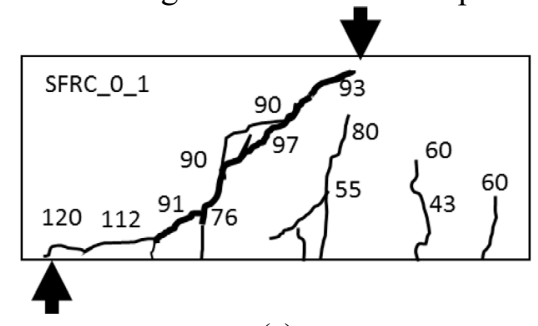

(a)

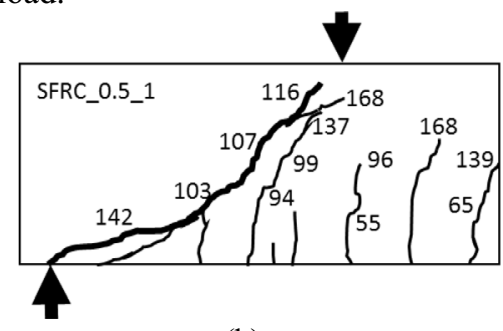

(b)

Fig. 4. Crack pattern in beams (a) Control beam; and (b) SFRC beam. 
In all beams, the shear crack was formed at distance of $250 \mathrm{~mm}$ from the support at the mid-height location of the beam. The crack angles within the shear region extending over the middle third of the beam are also nominally similar in all specimens, between 41 and 43 degrees with respect to the horizontal. The load responses of the SFRC beams are nominally similar to the load responses obtained from the control specimens, up to peak load of the control. The shear crack extends between the level of the rebar and the top of the beam at the peak load. Cracking in the matrix therefore does not appear to be influenced by the presence of discrete steel fibers. This indicates that the internal mechanism of resistance is essentially identical in both SFRC and control beams up to peak load. Failure in control specimens was very brittle, with very visible opening of the shear crack. The failure may therefore be attributed to the failure of the internal stress transfer across the shear crack. At corresponding loads, the crack opening in SFRC specimens are significantly smaller when compared with the control beams. The shear crack continued to open in a controlled manner in the $0.5 \%$ SFRC past peak load.

\section{Digital image analysis of shear cracks}

During the loading process, digital images were taken at regular intervals of load. These images were processed using the VIC $2 \mathrm{D}^{\mathrm{TM}}$ software to obtain the full-field surface displacements. Typical contours of displacement in the X-direction at two distinct points in the load response of a control beam are shown in Fig. 6. The formation of cracks are identified by a break in the contours. The use of DIC allows for accurate identification of cracks, which may not be delineated visually. The crack patterns identified using DIC were nominally similar to those obtained from visual examination. The use of DIC allows for tracking changes in the material response across a crack after the shear crack is identified. From a record of images, the location of the crack can be identified and the opening and shear displacements across the shear crack can be studied from a load point before the initiation of the crack. To understand the shear crack opening behavior in the beams, guage points identified with two sets of boxes (labelled G1 through G6) about 80 X80 pixels were considered at locations on either side of the crack such that the line joining their centers is perpendicular to the crack direction as shown in the Fig. 6(b). The exact location of the guage points was decided considering the load points close to failure, where the shear crack was fully established. The guage points are identified with the center of the box and were located in the shear region within the middle third portion of the beam. The location of the guage points were kept fixed in all images for analysis. The average values of displacements were obtained from within the area of each box from each location; the average horizontal and vertical displacements were obtained from the values of displacements of all the pixels within each box.

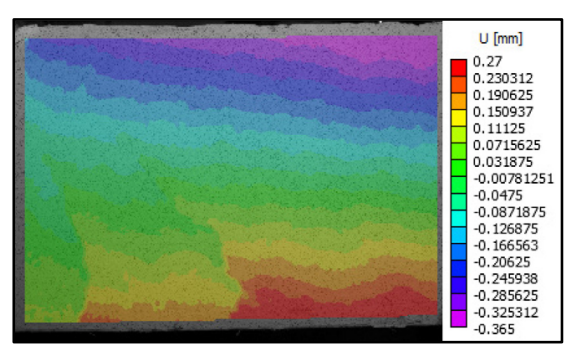

(a)

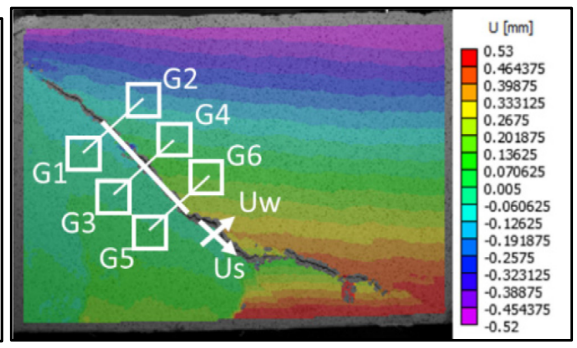

(b)

Fig. 5. Contour plot of displacement in X-direction from the SFRC_0_1 beam at different points on the load response: (a) at $95 \mathrm{KN}$ and (b) at $132 \mathrm{KN}$. 
Typical horizontal and vertical displacements from two pairs of points across the shear crack, located within the shear region (middle third of the beam) of the beam, were used to calculate the components of relative displacements in the directions which are perpendicular and parallel to the crack. The component of relative displacement which is parallel to the crack gives the slip across the crack $\left(U_{s}\right)$ and the component which is perpendicular to the crack gives the crack opening displacement across the crack $\left(U_{w}\right)$. The $U_{w}$ and $U_{s}$ obtained from the two points located at the mid-height of the beam, G3 and G4 are shown in Fig. 6. The $U_{w}$ and $U_{s}$ of the two guage points are initially identical with increasing load. The formation of the shear crack can be identified by the divergence of the displacements measured from the two guage points. With increasing load there is an increasing divergence in the displacements of the pair of guage points. The average slip and average crack opening displacement across the crack was determined as the average of the difference in the relative displacement from pairs of points G1 and G2, G3 and G4, G5 and G6.

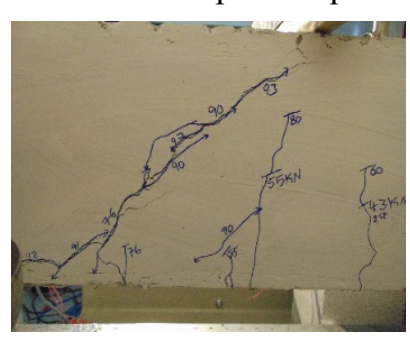

(a)

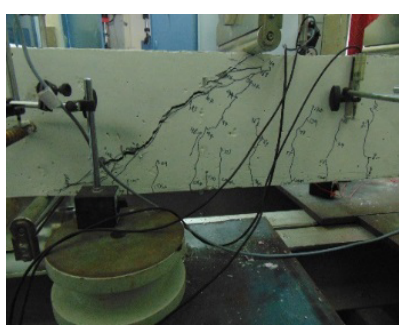

(d)

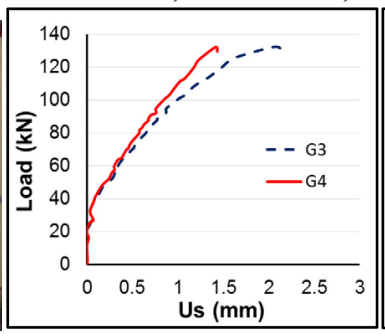

(b)

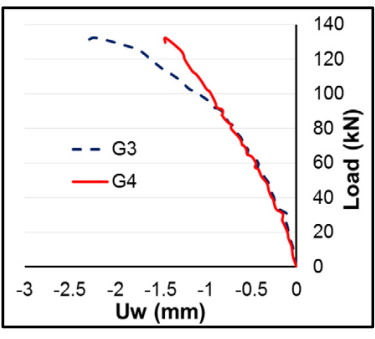

(c)

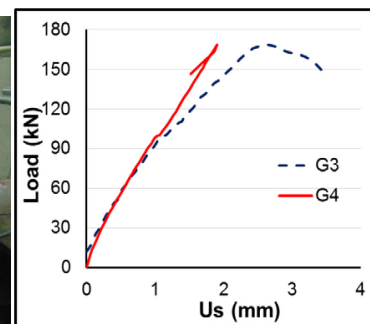

(e)

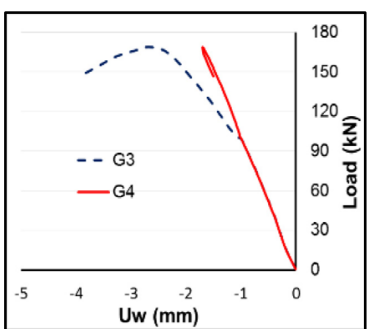

(f)

Fig. 6. A photograph showing crack pattern of (a) SFRC_0_1 (d) SFRC_0.5_1 beams; At G3 and G4, the variation of vertical displacement of (b) SFRC_0_1 (e) SFRC_0.5_1; horizontal displacements of (c) SFRC_0_1 (f) SFRC_0.5_1 beams. 


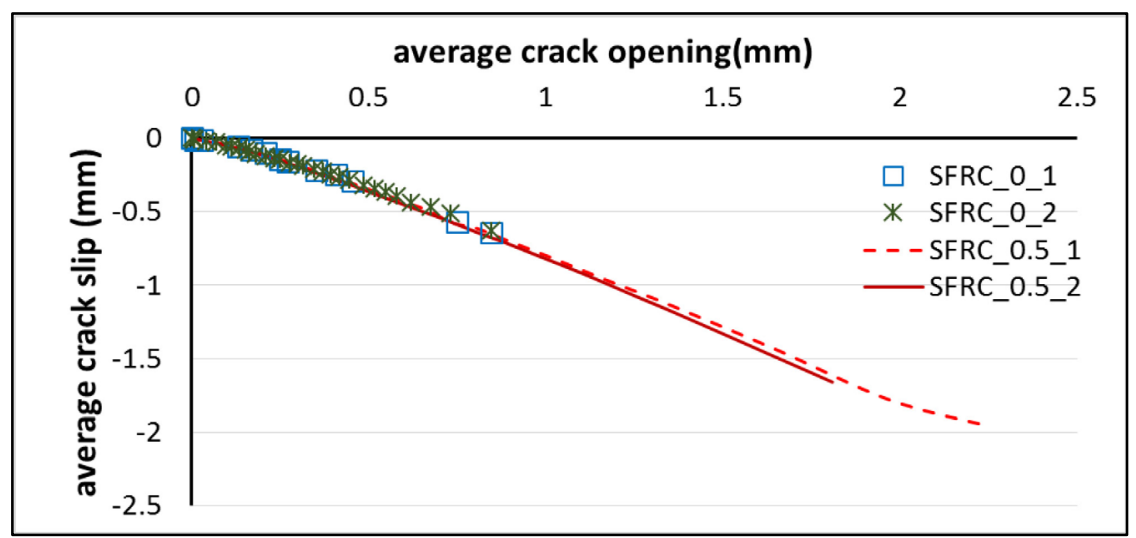

Fig. 7. Crack opening-slip response of control and SFRC beams.

The average crack slip as a function of the average crack opening across the primary shear crack formed in the pre-peak load response obtained from both control and SFRC beams is shown in Fig. 7. The resulting behavior obtained from the shear region indicates a dilatant behavior. There is an increase in crack opening associated with an increase in slip between the rough crack surfaces. With the application of load, after the onset of the shear crack, the crack opening increases nominally in linear manner with an increase in the average slip. The dilatant behavior (crack opening - slip response) exhibited by both control and the SFRC beams is identical. This suggests that the relationship between slip and crack opening is of the same origin. In the $0.5 \%$ SFRC beams, the crack slip and the crack opening continue to increase past the peak load for the control specimens.

A comparative analysis of the control and $0.5 \%$ SFRC beams is performed using the measured responses from each. The shear dilatant behaviors recorded from a control specimen (SFRC_0_1) and a 0.5\% SFRC beam (SFRC_0.5_1) are shown in Fig. 8(b) and Fig. 8(c), respectively. The load responses of the two beams are plotted in Fig. 8(a) for reference. The crack opening and the crack slip measurements at a load corresponding to the peak load in the control beam is marked in the dilatant behavior. At the peak load of the control specimen, both the crack opening and the crack slip in the SFRC beam are smaller than the corresponding values in the control specimen. The crack opening and the crack slip values recorded at the peak load in the response of the SFRC beam are comparable to the values obtained from the control specimen at peak load. The dilatant behavior, the general trend in the crack opening and crack slip relationship is not altered after the peak load. 


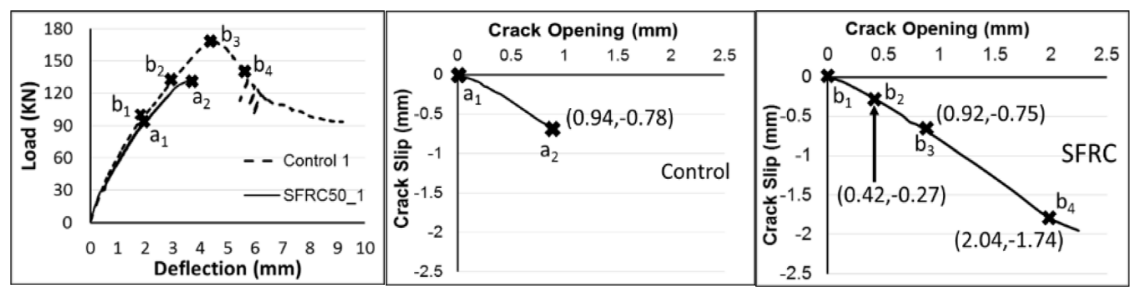

(a)

(b)

(c)

Fig. 8. (a) Load-response; Crack opening-slip response of (b) control_1 and (c) SFRC50_1 beams.

\section{Analysis of shear failure of beams}

The free body diagram of a part of beam in shear span for which one end is the crack plane is shown in Figure 9. Considering the diagonal crack at the end from experimental tests is essentially at $45^{\circ}$ to the horizontal (thick line shown in Fig 9a), the crack plane is idealized as a straight line inclined at $45^{\circ}$ as shown in the free-body diagram. The applied forces and the internal forces of resistance from concrete and reinforcement are as shown in the Fig $7 \mathrm{~b}$. The coordinate system for evaluating forces is taken in directions which are aligned parallel and perpendicular to the crack plane. The internal forces of resistance include, the resultant normal compressive force on the crack plane (C) from concrete acting at a distance $\mathrm{z}$ from the top fiber of the beam, shear resistance across the crack coming from the aggregate interlock and other factors (S), the tensile force in the reinforcement $(\mathrm{T})$, and the dowel force from the reinforcement (D). The resultant compressive force (C) is the vectorial sum of the normal forces acting on the crack plane. S represents the shear demand on the inclined crack plane resulting from the requirement of equilibrium of forces in a direction parallel to the crack. The shear resistance generated across the crack face would depend upon the level of compression (C) and the may take as $\mu^{*} \mathrm{C}$ where $\mu$ is the constant of proportionality, which depends on the roughness of the crack surface and the contact area of the rough crack.

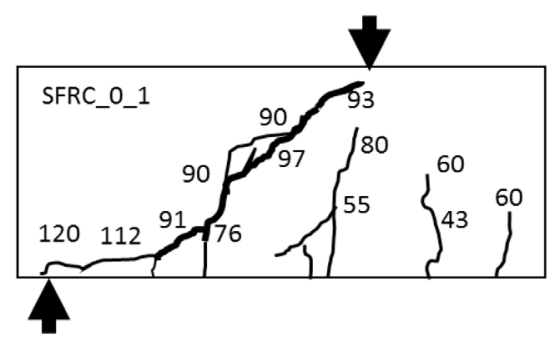

(a)

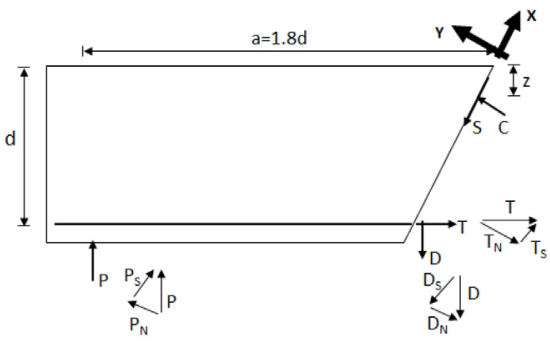

(b)

Fig. 9. (a) crack pattern of control beam; (b) Free body diagram of the part of the control beam in shear span.

By taking components of forces along the crack plane as shown in the Figure 9,

$$
\begin{aligned}
& \boldsymbol{T}_{N}=T_{S}=T / \sqrt{2} \\
& \boldsymbol{P}_{N}=P_{s}=P / \sqrt{2} \\
& \boldsymbol{D}_{N}=D_{s}=D / \sqrt{2}
\end{aligned}
$$


Taking moment about top right most point of the beam and assuming $\mathrm{z}$ is small, the moment contribution from $\mathrm{C}$ is insignificant,

$$
\boldsymbol{T} * \boldsymbol{d}=P^{*}(1.8) d-(D * d)
$$

By considering the force equilibrium along Y-axis,

$$
\begin{aligned}
& \boldsymbol{\Sigma} \boldsymbol{F}_{\boldsymbol{y}}=P_{N}-T_{N}+C-D_{N}=0 \\
& \boldsymbol{C}=T_{N}-P_{N}+D_{N}
\end{aligned}
$$

By considering the force equilibrium kalong $\mathrm{X}$-axis,

$$
\begin{aligned}
& \boldsymbol{\Sigma} \boldsymbol{F}_{\boldsymbol{x}}=P_{S}+T_{S}-S-D_{s}=0 \\
& \boldsymbol{S}=T_{S}+P_{S}-D_{s}
\end{aligned}
$$

Considering Equation (5), the tensile stress obtained from the strain gauge data at the crack location.

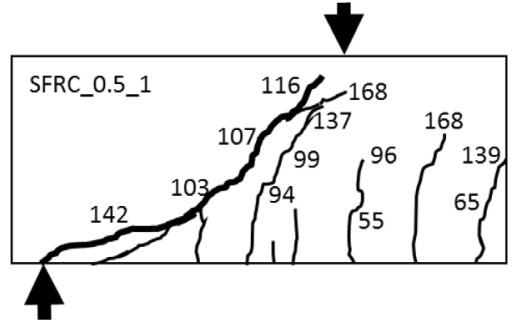

(a)

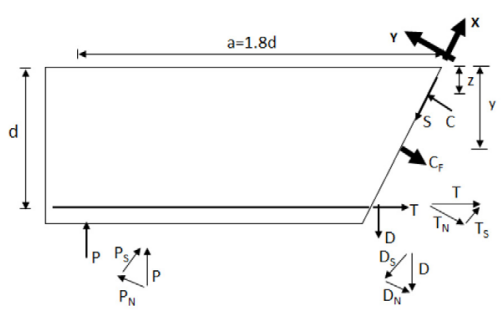

(b)

Fig. 10. (a) Crack pattern of beam with $0.5 \%$ fibers, (b) Free body diagram of the part of the SFRC beam in shear span

In fiber reinforced concrete beams, due to the presence of fibers, there will be an additional average normal resistant force across the crack associated with opening of the crack. The additional the crack closing stresses are identified with $C_{F}$ in Fig 10.The fiber force $\left(C_{F}\right)$ is shown acting at a distance $y$ from the top of the beam (the Fig 10).

Taking moment about point A shown in the figure,

$$
\Sigma \boldsymbol{M}=T^{*} d-P^{*}(1.8 d)+C_{F} *(\sqrt{2} y)+\left(D^{*} d\right)=0
$$

Considering force equilibrium along $\mathrm{Y}$ axis,

$$
\begin{aligned}
& \boldsymbol{\Sigma} \boldsymbol{F}_{\boldsymbol{y}}=P_{N}-T_{N}+C-C_{F}-D_{N}=0 \\
& \boldsymbol{C}=T_{N}-P_{N}+C_{F}+D_{N}
\end{aligned}
$$

Considering force equilibrium along $\mathrm{X}$ axis,

$$
\begin{aligned}
& \boldsymbol{\Sigma} \boldsymbol{F}_{\boldsymbol{x}}=P_{S}+T_{S}-D_{s}-S=0 \\
& \boldsymbol{S}=T_{S}+P_{S^{-}} D_{s}
\end{aligned}
$$

The resultant compressive force (C) on the crack face now contains an additional contribution of the fiber force and is higher than the corresponding value in control beam. After peak, the value of $\mathrm{C}$ depends on the crack closing stresses available as $\mathrm{C}_{\mathrm{F}}$. Even at the higher displacement which results in larger crack opening, the fibers provide crack bridging stresses, which ensures contact compressive stress across the compression along the crack plane. This allows the shear carrying capacity across the crack face and the beam continues 
to carry load. From this it can be established that fibers do help in transfer of shear across the shear crack with the additional compression coming across the crack with presence of fibers.

\section{Summary and conclusions}

Addition of fibers do not influence shear cracking load or the crack angle. There is continuous increase in slip across the crack faces of the dominant shear crack with increasing load. The crack exhibits a dilatant response, where the increase in slip displacement produces an increase in crack opening. Shear slip to crack opening relationship of a rough shear crack up to peak is not altered by the fibers. In control beams, when the shear crack reaches the level of the flexural reinforcement, it grows along the rebar up to the support point and the beam fails by splitting along this crack as the resistance coming from the aggregate interlock is lost with increased crack width. Fibers are effective after the formation of crack and sustain the shear transfer ability across the rough crack. This helps sustain shear load carrying capacity of the beam. Sudden splitting along the shear crack is suppressed by the fibers bridging the crack leading to a continuous resistance to load for a larger deflection of the beams. With the addition of steel fibers failure mode changes from brittle to ductile.

Analysis of shear response of reinforced concrete beam shows that control specimens failed when compression generated by rebar is insufficient to sustain aggregate interlock after yielding of the flexural reinforcement. In fiber reinforced beams, the additional compression across the crack provided by the fibers helps sustain the shear transfer across the crack.

\section{References}

1. M. A. Mansur, K. C. G. Ong, \& P. Paramasivam., Shear strength of fibrous concrete beams without stirrups. Journal of Structural Engineering, 112(9), 2066-2079, (1986).

2. A.K. Sharma., Shear strength of steel fiber reinforced concrete beams. In $A C I$ Journal Proceedings, Vol. 83, No. 4. (1986).

3. R. Narayanan, \& I. Y. S. Darwish, (1987)., Use of steel fibers as shear reinforcement. ACI Structural Journal, Vol. 84(3).

4. S. A. Ashour, G. S. Hasanain, \& F. F. Wafa., Shear behavior of high-strength fiber reinforced concrete beams. ACI Structural Journal, Vol. 89(2), (1992).

5. V. C. Li, R. Ward, \& A. M. Hmaza, (1992). Steel and synthetic fibers as shear reinforcement. ACI Materials Journal, Vol. 89(5), (1992).

6. K. H. Tan, K. Murugappan, \& P. Paramasivam., Shear behavior of steel fiber reinforced concrete beams. Structural Journal, Vol. 90(1), 3-11, (1993).

7. M. Imam, L. Vandewalle, F. Mortelmans, \& D. Van Gemert., Shear domain of fibrereinforced high-strength concrete beams. Engineering structures, Vol. 19(9), 738747, (1997).

8. Y. K. Kwak, M. O. Eberhard, W. S. Kim, \& J. Kim., Shear strength of steel fiberreinforced concrete beams without stirrups. ACI Structural Journal, Vol. 99(4), (2002).

9. S. H. Cho, \& Y. I. Kim., Effects of steel fibers on short beams loaded in shear. Structural journal, vol. 100(6), 765-774, (2003).

10. C. Cucchiara, L. La Mendola, \& M. Papia., Effectiveness of stirrups and steel fibres as shear reinforcement. Cement and Concrete Composites, Vol. 26(7), 777-786, (2004). 
11. D. R. Sahoo, \& N. Kumar., Monotonic behavior of large-scale SFRC beams without stirrups. Engineering Structures, Vol. 92, 46-54, (2015).

12. D. R. Sahoo, S. Bhagat, \& T. C. V. Reddy., Experimental study on shear-span to effective-depth ratio of steel fiber reinforced concrete T-beams. Materials and Structures, Vol. 49(9), 3815-3830, (2016).

13. ACI 318-08, Building code requirements for structural concrete (ACI 318-08) and commentary, American Concrete Institute, Farmington Hills, MI, (2008)

14. R. Park, \& T. Paulay., Reinforced concrete structures. John Wiley \& Sons, (1975).

15. J. G. MacGregor, J. K. Wight, S. Teng, \& P. Irawan., Reinforced concrete: mechanics and design (Vol. 3). Upper Saddle River, NJ: Prentice Hall, (1997).

16. G. Winter, \& A. Nilson., Design of concrete structure, $9^{\text {th }}$ ed., McGraw Hill, New York, (1986).

17. M. Khuntia, B. Stojadinovic, \& S. C. Goel., Shear strength of normal and highstrength fiber reinforced concrete beams without stirrups. Structural Journal, Vol 96(2), 282-289, (1999).

18. L. Vandewalle., Design method for steel fiber reinforced concrete proposed by RILEM TC 162-TDF. In P. Rossi, \& G. Chanvillard (Eds.), Fifth International RILEM Symposium on Fibre-Reinforced Concrete (FRC) (pp. 51-64). RILEM Publications SARL, (2000).

19. L. Vandewalle., RILEM TC162-TDF: Test and Design methods for Steel Fibre Reinforced Concrete: Bending test (final recommendation). Materials and Structures, Vol. 35, 579-582, (2002).

20. M.P. Collins, E. C. Bentz, E. G. Sherwood, \& J. K. WIGHT., Where is Shear Reinforcement Required? Review of Research Results and Design Procedures. ACI structural journal, Vol. 106(4), 556-559, (2009).

21. J. C. Walraven., Aggregate interlock: a theoretical and experimental analysis (Doctoral dissertation, TU Delft, Delft University of Technology), (1980).

22. J. C. Walraven, \& H. W. Reinhardt., Theory and experiments on the mechanical behaviour of cracks in plain and reinforced concrete subjected to shear loading. HERON, Vol. 26 (1A), (1981).

23. J. C. Walraven, Fundamental analysis of aggregate interlock. Journal of the Structural Division, ASCE, Vol. 107(11), 2245-2270, (1981).

24. K. V. Subramaniam, J. Popovics, and S. P. Shah., Testing Concrete in torsion: Instability analysis and Experiments, Journal of Engineering Mechanics, American Society of Civil Engineers (ASCE), Vol. 124 (11), pp. 1258-1268, (1998).

25. IS 1786, High strength deformed steel bars and wires for concrete reinforcement, Bureau of Indian Standards. New Delhi, (2008).

26. ASTM, C. 1609/C 1609M-06. Standard Test Method for Flexural Performance of Fiber-Reinforced Concrete (Using Beam with Third-Point Loading), ASTM International, USA, (2006).

27. M. A. Sutton, W. J. Wolters, W. H. Peters, W. F. Ranson, \& S. R. McNeill., Determination of displacements using an improved digital correlation method. Image and vision computing, Vol. 1(3), 133-139. (1983).

28. M. A. Sutton, S. R. McNeill, J. Jang, \& M. Babai., Effects of subpixel image restoration on digital correlation error estimates. Journal of Optical Engineering, Vol. 27(10), 870-877, (1988).

29. C. Carloni, \& K. V. Subramaniam., Direct determination of cohesive stress transfer during debonding of FRP from concrete. Composite Structures, Vol. 93(1), 184-192, (2010). 
30. K. C. Reddy, and K. V. Subramaniam, "Crack Propagation and Post cracking Behavior of Macrosynthetic Fiber Reinforced Concrete," accepted for publication in Magazine of Concrete Research, (2017). 